Beth Jenkins, University of Essex, Department of History

This is an original manuscript / preprint of an article published by Taylor \& Francis in Cultural and Social History on 18 May 2020, available online: http://www.tandfonline.com/10.1080/14780038.2020.1764463.

\title{
Gender, embodiment and professional identity in Britain, c.1890-1930
}

This article examines how the body, clothing and deportment were important elements in women's negotiation of gendered professional identities during late nineteenth and early twentieth-century Britain. That abstract ideals of professionalism had become synonymous with male characteristics was problematic for women: to emulate masculine attire or behaviour compromised their gender identity, but to embody traits associated with femininity could undermine their professional authority. Focusing particularly on women doctors and academics, the article argues that by the interwar decades some women found it easier to reconcile embodied gender and professional identities, albeit in restricted ways. This was partly because of successes in female professionalisation and the increased visibility of female "role models" in certain occupations which, in turn, influenced the selfshaping of successive generations.

Keywords: gender, class, body, clothing, physical appearance, professional identity

\section{Introduction}

Recalling her time as a medical student in Edinburgh during the first decade of the twentieth century, Dr Isabel Emslie Hutton wrote:

If we were feminine in attire or demeanour or had the effrontery to wear high heels, a dizzy hat or the charming 'Merry Widow' curls then in vogue, it was deemed that we could not be serious; worse still, it might be argued that we were too pretty or too nice to be studying medicine and this was considered even more devastating [...] The plain dowdy women students were on the whole preferred, for the men could then hoot with laughter and label them as freaks, jokes or monsters. In fact, it was apparently impossible to strike the happy mean and to be just an ordinary young woman. ${ }^{1}$

Hutton highlights the difficult cultural terrain that women doctors had to navigate in early twentieth-century Britain. To be feminine in attire and show interest in their personal appearance, she outlined, was considered frivolous and undermined professional credibility. Yet plainness of

\footnotetext{
${ }^{1}$ Isabel Hutton, Memories of a Doctor in W ar and Peace (London, 1960), pp.39-40.
} 
dress or limited attention to self-presentation risked being labelled "sexless" and becoming the subject of ridicule and humour. Writing her memoir in the late 1950s, Hutton's recollections were also shaped by and drew upon discursive frameworks which had evolved alongside widespread socioeconomic changes for women across the first half of the twentieth century. ${ }^{2}$ Reflecting on this intervening period, Hutton noted that more practical clothing and shorter hair had "increased women's confidence, independence and emancipation a hundredfold". ${ }^{3}$ Whether sartorial changes were a cause - or, indeed, an effect - of advancements in women's social position is perhaps not so clear. But Hutton's inclusion of these details in the narration of her life story is nonetheless significant and demonstrates that her physical appearance was intimately connected to how she both remembered and reconciled her identities as a woman and a professional.

The purpose of this article is to examine how women negotiated the tension they faced between their gender and professional identities through their personal appearance during a formative period in their movement into male-dominated occupations. The expansion of girls' education and increased access to higher education, in tandem with organised feminist campaigns, created new employment opportunities for middle-class women by the turn of the twentieth century. While a rich body of scholarship has charted the uneven and protracted nature of their movement into various occupations, recent studies have begun to unpick the more insidious ways masculine professional cultures continued to marginalise women upon their entry. ${ }^{4}$ Other historians have fruitfully shown how women, too, engaged in professionalising strategies in response to exclusionary practices: forging their own socio-spatial cultures, founding associations and institutions, pursuing forms of accreditation, and negotiating professional identities vis-à-vis other women workers. ${ }^{5}$ Yet, the significance of the body in the formation of professional identities

\footnotetext{
2 Penny Summerfield, Histories of the Self, Personal Narratives and Historical Practice (Abingdon, 2018), p.79, p.84.

${ }^{3}$ Hutton, Memories of a Doctor, p.64.

${ }^{4}$ For medicine and academia, see: E. Moberly Bell, Storming the Citadel: The Rise of the Woman Doctor (London, 1953); Catriona Blake, The Charge of the Parasols: Women's Entry to the Medical Profession (London, 1990); Mary Ann Elston, 'Women Doctors in the British Health Services: A Sociological Study of their Careers and Opportunities' (Unpublished doctoral thesis, University of Leeds, 1986); Carol Dyhouse, No distinction of sex? Women in British universities 1870-1939 (London, 1995). Studies of gendered professional cultures include: Ren Pepitone, 'Gender, Space, and Ritual: Women Barristers, the Inns of Court, and the Interwar Press', Journal of Women's History, 28, 1 (2016); Carol Dyhouse, 'Women Students and the London Medical Schools, 1914-1939: The Anatomy of a Masculine Culture', Gender \& History, 10, 1 (1998).

5 Anne Witz, Professions and Patriarchy (London, 1992); Philippa Haughton, 'Fashioning Professional Identity in the British Advertising Industry: The Women's Advertising Club of London, 1923-1939' in Leah Armstrong and Felice McDowell (eds), Fashioning Professionals: Identity and Representation at Work in the Creative Industries (London, 2018); Zoë Thomas, 'At Home with the Women's Guild of Arts: gender and professional identity in London studios, c.18801925', Women's History Review, 24, 6 (2015); Ruth Livesey, 'The politics of work: feminism, professionalisation and women inspectors of factories and workshops', Women's History Review, 13 (2004); Angela Woolacott, 'From moral to professional authority: secularism, social work, and middle-class women's self-construction in World War 1 Britain', Journal of Women's History, 10 (1998).
} 
- whereby the mind and expertise were, in theory, privileged over physicality - has not been fully explored. Whilst historians have remarked on the scrutiny that women who transgressed gendered norms endured in relation to their appearance, little attention has been given to the impact that these caricatures had on women's self-identities. This article seeks to highlight some of the ways professional authority was linked to the gendered body in public representations, but also the personal impact that this had on women through analysis of their own testimonies.

The article has two interrelated arguments. First, it highlights that physical appearance, dress and the body provided tangible signifiers of professional identity and were therefore important components in women's negotiation into the professional workforce. That abstract ideals of professionalism were firmly associated with male characteristics was problematic for women: to downplay cultural markers of femininity compromised their gender identity, yet any displays of femininity risked charges of frivolity and undermined one's professional credibility. Secondly, the article suggests that, despite clear continuities with the pre-war years, some women found it easier to reconcile tensions between their embodied gendered and professional identities by the interwar decades. The changing political and cultural context, along with increasing numbers of women in formal education and the professional workforce, provided some women with new cultural scripts and institutional settings to forge alternative feminine identities and styles. By using a generational lens, the article shows that a crucial factor in their self-shaping was visible representation of women in similar occupational roles, who, in turn, enabled some of their successors to adopt more confident feminine professional personas in their bodily presentation.

The article is structured as follows. It begins by introducing the key concepts and historical contexts and showing how gendered embodiment and professional identity were intertwined. Drawing on the negative caricatures and regulations women faced, section two examines how gendered physical traits were linked to professional authority in broader society and culture. The final part of the article focuses on women's own testimonies: section three explores the collective identities women doctors forged in women's medical institutions, and section four uses women's autobiographical and professional writing to analyse how they remembered and constructed a professional self in relation to their appearance. The article focuses primarily on women doctors and academics, but comparisons are drawn with other occupations where appropriate. Women working in medicine and academia throughout the late nineteenth and early twentieth century often operated in separate women's cultures on the margins of a broader male-dominated occupational culture. Most of these early generations had experience of all-female institutions 
through their education and work: in girls' schools, women's university colleges, and women's medical schools and hospitals. Crucially, these institutions provided alternative spaces for socialisation and to encounter visible representations of women in similar occupational roles.

\section{Professional Identity and Gendered Embodiment in Historical and Historiographical Context}

By the late nineteenth century professionalism and middle-class masculinity were firmly entwined as the workplace became a key site for the construction of masculine identity. ${ }^{6}$ Significantly, contemporary notions of manliness were premised largely on external qualities: as Michael Roper summarised, “it was from a man's comportment, his physical appearance and performance, that inner qualities were judged". ${ }^{7}$ Historians have suggested that, partly in response to major changes occurring in nineteenth-century society, codes of manliness which highlighted a "rough and tough masculinity" were redefined and reasserted. ${ }^{8}$ An embodied muscular masculinity outside of the workplace became increasingly important as constructions of masculinity were affected by changing employment structures whereby new technology and the rise of sedentary jobs such as salaried office workers and clerks posed a threat to men's "physical significance". ${ }^{9}$ During this period, the suit also emerged as the ubiquitous male attire for men across all social classes which, Katrina Honeyman argued, was tied to a distinct masculine identity centred on "respectability, rationality, sobriety and diligence". ${ }^{10}$

Middle-class women's movement into formal education, growing economic independence and wider campaigns for political reform presented a significant challenge to men's identity as the working sex. ${ }^{11}$ As a consequence of these societal changes, masculinity and femininity became essentialised in a more absolute sense than before. A major element in this shoring up of gender divisions in late nineteenth-century society was related to the body. Campaigns for and against women's higher education and paid work during the final quarter of the century led to extensive

\footnotetext{
${ }^{6}$ John Tosh 'What should historians do with masculinity? Reflections on nineteenth-century Britain', in Tosh (ed.), Manliness and Masculinities in Nineteenth-Century Britain: Essays on Gender, Family and Empire (New York, 2005), p.37.

${ }^{7}$ Michael Roper, 'Between Manliness and Masculinity: The "War Generation" and the Psychology of Fear in Britain, 1914-1950', Journal of British Studies, 44, 2 (2005), pp.347-8.

8 Ava Baron, 'Masculinity, the Embodied Male Worker, and the Historian's Gaze', International Labor and Working-Class History, 69 (2006), pp.146-7.

9 Joanne Begiato, 'Between Poise and Power: Embodied Manliness in Eighteenth- And Nineteenth-Century British Culture', Transactions of the Royal Historical Society, 26 (2016), p.135.

${ }^{10}$ Katrina Honeyman, 'Following Suit: Men, Masculinity and Gendered Practices in the Clothing Trade in Leeds, England, 1890-1940', Gender \& History, 14, 3 (2002), p.428.

11 Tosh 'What should historians do with masculinity?', p.37.
} 
scientific and political engagement with the relationship between the female body and mind. Opposition to women's employment in various fields sought to legitimise their concerns by placing emphasis on psychological and physiological differences between the sexes: critics argued that women were not mentally or physically strong enough for the competitive environment of the professions, and believed that higher education and paid employment was detrimental to women's health, beauty and fertility. ${ }^{12}$ Such assumptions about the link between the size and quality of the brain and muscular development of the body ensured that the gendered body was firmly linked to notions of professional expertise and authority in broader society and culture.

Indeed, feminist scholars such as Anne Witz have long shown that the generic concept of the "professional" is a gendered one. ${ }^{13}$ This was entwined with historic processes of professionalisation that were both explicitly and implicitly premised on boundaries of exclusion. Most overtly, professionalisation was underpinned by institutional locations, such as universities and professional associations, which various social groups had differing degrees of access to. As important sites of socialisation, their exclusivity and dominant social composition - largely demarcated by gender, class and race - meant that certain bodies and attributes became implicitly associated with and revered as "natural" professional qualities. For instance, physicality, height, voice, accent, clothing and deportment were all intimately connected to these gendered expressions of professional authority. Even when some of the structural barriers to entry slowly began to dissipate following wider access to education and legislative gains for women, the cultural legacy of exclusionary practices had enduring effects for those groups who did not fit the prescribed template.

Women's construction of individual and collective gendered professional identities has attracted significant historiographical attention. ${ }^{14}$ This is linked to wider considerations about whether women used strategies of gender difference or assimilation to legitimise their professional authority. Historians have detailed how contemporaries highlighted women's supposed essentialist qualities - usually centred on social maternalism - to carve unique occupational roles for them in certain fields, or justify their exclusion from others. Acknowledging that women drew upon fluid frameworks of identity, scholarship largely suggests that by the interwar decades women began to

\footnotetext{
${ }^{12}$ Katharina Rowold, The Educated Woman: Minds, Bodies and Women's Higher Education in Britain, Germany, and Spain, 1865-1914 (London, 2010).

${ }^{13}$ Witz, Professions and Patriarchy, p.5; Anne Logan, 'Professionalism and the impact of England's first women justices, 1920-1950', Historical Journal, 49 (2006).

${ }^{14}$ For a good overview, see: Krista Cowman and Louise A. Jackson, 'Middle-Class Women and Professional Identity', Women's History Review, 14, 2 (2005).
} 
articulate a more confident feminine version of professional expertise in some occupations alongside legislative gains, the expansion of education and healthcare, and welfare reforms. Yet notions of gender difference could simultaneously be a problematic basis for women's professional status. Arguments premised on women's “innate" caring and maternal qualities provided the justification for pigeonholing them into certain occupational specialisms which, in turn, became associated with lower prestige and remuneration. To date, historians' analysis of these debates has predominantly been on the immaterial performance of gender.

Feminist theorists have long observed that physical differences have been used to explain and justify the different - and unequal - social position and cognitive abilities of men and women. ${ }^{15}$ Consequently, early scholarship focused on breaking this "deterministic link between corporeal characteristics, mental faculties and social role" by drawing a clear distinction between sex and gender. ${ }^{16}$ More recently, theorists have problematised binary notions of the body and self: they have sought to understand how the meanings attached to bodily difference informs one's sense of self and how this is "negotiated intersubjectively" through the response of others. ${ }^{17}$ The notion of embodiment - experiencing the world through bodily perception - is a fruitful one here. ${ }^{18}$ Embodiment foregrounds the physical materiality of the lived body, as well as its social and cultural construction. ${ }^{19}$ As a key marker of identity, the body was an integral component in cultural constructions of the "professional" and, in turn, intimately related to women's construction of a professional self. In her research on contemporary workplace culture, Kathryn Haynes highlights the significance of the physical body in the formation of the personal and professional self, whereby "the body becomes a vehicle for displaying conformity, or indeed nonconformity, to gendered social norms". ${ }^{20}$

Using embodiment as an analytical lens, then, offers an insight into the way gendered notions of professionalism were physically displayed in relation to the body and the effect this had, in turn, on women's formation of professional identities. The following sections explore these two interrelated components: firstly, the social and cultural constructions of the embodied female professional, and, secondly, how women experienced and responded to these gender prescriptions

\footnotetext{
${ }^{15}$ Elizabeth Grosz, Volatile Bodies: Toward a Corporeal Feminism (Bloomington, 1994), p.14.

${ }^{16}$ Kathleen Lennon, 'Feminist Perspectives on the Body', The Stanford Encyclopedia of Philosophy (Fall 2019 Edition).

${ }^{17}$ Lennon, 'Feminist Perspectives on the Body'.

${ }^{18}$ Kathleen Canning, 'The Body as Method? Reflections on the Place of the Body in Gender History', Gender \& History, 11,3 (1999), p.505.

${ }^{19}$ Canning, 'The Body as Method?, p.505.

${ }^{20}$ Kathryn Haynes, 'Body Beautiful? Gender, Identity and the Body in Professional Services Firms', Gender, Work and Organization, 19, 5 (2012), p.493.
} 
and caricatures. Whilst press reports and prescriptive literature provide an insight into top-down representations and regulations of women's appearance in broader culture, sources which offer insights into the body as "a site of experience, memory, or subjectivity" in the past are less accessible and more fragmentary. ${ }^{21}$ Nonetheless, through the self-fashioning advice they gave their successors, personal archival material, and autobiographical and professional writing, we can gain a glimpse into how women conceptualised and negotiated their gendered professional identities in relation to their appearance.

\section{Press Representations, Prescriptive Advice and Professional Discrimination}

In literary and visual culture, images of women who transgressed gender norms in their work often depicted them through physical transgressions. This coalesced into several cultural motifs by the turn of the twentieth century. The plain-dressed, bespectacled, graduate with tightly drawn-back hair - caricatured in the New Woman - became a symbol of women's supposed physical and intellectual freedom. "Bluestocking", too, was a catch-all term for a woman who transcended acceptable boundaries of femininity through her education and work, and was still in usage throughout the interwar years. Significantly, contemporaries increasingly used it as a derogative slur to allude to an "indescribable" look or "intellectual cast of features". ${ }^{23}$ During the First World War, the widespread movement of women into occupations traditionally seen as the preserve of men further destabilised categories of gender. Unflattering depictions of women surgeons, with harsh features and attired in manly garb, coexisted alongside celebratory and idealised portraits of nurses in wartime hospitals. ${ }^{24}$ Throughout the interwar decades, press scrutiny of the physical appearance of the first cohorts of women MPs and entrants into newly-opened professions such as law continued unabated. ${ }^{25}$ Their clothing, physique, facial features, voice and manner generated considerable media attention, and provided a tangible focal point for broader cultural anxieties about gender roles.

In response to these societal concerns that paid employment would compromise their femininity, women faced extensive attempts to regulate their physical appearance and deportment from a variety of sources. The increasing number of middle-class women who entered paid

\footnotetext{
${ }^{21}$ Canning, 'The Body as Method?, p.502.

${ }^{22}$ Gillian Sutherland, In Search of the New Woman: Middle-Class Women and Work in Britain 1870-1914 (Cambridge, 2015).

${ }^{23}$ Western Mail, 3 October 1887.

${ }^{24}$ Punch, 4 August 1915.

${ }^{25}$ Laura Beers, ‘A Model MP? Ellen Wilkinson, Gender, Politics and Celebrity Culture in Interwar Britain', Cultural and Social History, 10, 2 (2013).
} 
employment during the latter years of the nineteenth century facilitated the production of women's career advice manuals, which were part of broader trend of prescriptive literature aimed at this demographic. Readers were presented with a comprehensive overview of the types of occupations available to them and usually detailed the cost and length of training, financial prospects and qualities considered necessary to succeed. Whilst intended to give a summary of openings, attention was also given to the body and self-presentation. As a didactic genre removed from the realities of day-to-day life, these manuals provided models of behaviour and appearance for women which were often concerned with upholding gender prescriptions.

Career advice manuals continually highlighted the importance of personal conduct and demeanour as visual cues of class status and gender conformity. One publication, in 1903, lamented that "uncouthness in dress, or manner, or movement" was ingrained in the minds of the public in relation to medical women. ${ }^{26}$ Advising prospective doctors to adopt a heightened femininity to counter such stereotypes, the author advocated "good manners, a soft, refined voice, ... [and to not] despise those little touches of colour or ornaments which may add so much to the general pleasing effect of dress." ${ }^{27}$ Particular attention, too, was given the self-conduct of women in educational settings who were considered to be role models to pupils and students, often in a gender segregated education system. In academia, intellectual ability alone was considered insufficient, without the appropriate "manner, appearance, speech [and] tone". ${ }^{28}$ Referring to the qualities deemed desirable for a teacher, one manual outlined that "on her personal appearance, depends to a very large degree her efficiency". ${ }^{29}$ Explicitly linking physical appearance with professional competency, the author continued: "the most solid worth and scholarly attainments may be seriously detracted from by a bad presence, a harsh voice, some unhappy absurdity of manner". ${ }^{30}$ As clear signals of gender and social status, women's appearance, manners and selfconduct were often considered more important than academic achievements or occupational skill.

Hierarchies of professional authority were also demarcated through the gendered body: in particular, physicality could be a marker of the prestige of the occupation in a different way for women than men. For roles such as nursing and teaching, physical strength and the manual nature

\footnotetext{
${ }^{26}$ Ethel M. Lamport, 'Medicine as a Profession for Women', in Ethel McKenna (ed.), Education and the Professions (London, 1903), p.257.

${ }^{27}$ Lamport, 'Medicine as a Profession for Women', p.263.

${ }^{28}$ Vyrnwy Biscoe, 300 Careers for Women (London, 1932), p.209.

${ }^{29}$ Beatrice Orange, 'Teaching as a Profession for Women', in Ethel McKenna (ed.), Education and the Professions (London, 1903), p.90.

30 Orange, 'Teaching as a Profession for Women', p.90.
} 
of the job was emphasised. Referring to prospective nurses, one manual outlined that "candidates should be physically strong and of average height and build". ${ }^{31}$ A "strong" physique was cited as an important prerequisite for most healthcare jobs, but particularly revered for women considering nursing or teaching. But those very qualities considered a necessity for women-dominated occupations were often deployed in counter arguments when women posed a threat to masculine professional cultures. In medicine, law and academia, for example, opponents of women's entry cited the physically tiring and arduous nature of the job to highlight women's unsuitability for the job or relegation to roles "more congenial to her nature". ${ }^{32}$

Whilst discrimination often operated in more subtle and insidious ways, the survival of references supporting women's job applications provide clear evidence of how perceived physical attractiveness and bodily traits could affect their job prospects. When Dr Mary Williams applied for the Chair in French Language and Literature at the newly-founded University College Swansea in 1921, a letter in support of her application was keen to stress her "unusual health and strength". 33 Her colleague at King's College London, Victor Spiers, wrote that her strong constitution enabled her "to stand even prolonged strain of work and give her lectures with perfect regularity." ${ }^{34}$ Spiers outlined traits he thought the interview panel would consider desirable, but he was also responding to the argument that women's supposed physical inferiority rendered them unsuitable for certain occupational roles. Other women were perhaps less fortunate in the testimonies their referees supplied. In 1927, Glamorgan Training College advertised for a lecturer in education and senior methods. A referee of one of the candidates noted how she was "under some disadvantage on the grounds of physique as she is rather short and slight and perhaps not attractive in appearance". ${ }^{35}$ Using physical attractiveness as a quality to distinguish between them, a former lecturer of two candidates for a position at the same college several years prior noted that "possibly you might think any advantage in the matter of personal appearance would lie with Miss Morris". ${ }^{36}$

Women applicants, too, clearly recognised the importance of their physical presence on their employment prospects. Waiting to hear back from an interview she had at King's College in 1925, historian Dr Sophia Weitzman wrote to her former academic mentor at Manchester, Professor T.

\footnotetext{
31 Biscoe, 300 Careers for Women, p.165.

32 British Medical Journal, 27 July 1918.

${ }^{33}$ National Library of Wales [NLW]: GB0210, 2459, Mary Williams' Application for the Chair of French Language and Literature University College, Swansea, with testimonials, 1921.

${ }^{34}$ NLW: GB0210, 2459.

${ }^{35}$ Glamorgan Archives [GA]: ECOLLB/11/1-11, Glamorgan Training College, Staff Records: Appointments (Women), 1927.

36 GA: ECOLLB/11/1-11, 1925.
} 
F. Tout: "I'm beginning to despair of ever getting anything on an interview. These jobs go to the tall, capable-looking women and I'm neither: College lecturers are a type and 'insignificant me', doesn't look the part." ${ }^{37}$ Explicitly equating "capable-looking” and “tall”, Weitzman highlights a link between notions of professional authority and physical traits such as height and stature. Through exposure to derogative caricatures in the press and the reception they received from contemporaries, women were therefore acutely conscious on a personal level that their physical appearance could be equated with their occupational competency.

\section{Women Doctors, Self-fashioning and Collective Professional Identities}

The mentorship women provided their successors offers an interesting counterpoint to the prescriptive manuals analysed in the previous section. During the final quarter of the nineteenth century, women founded separate medical schools and hospitals to enable them to gain the necessary professional training and positions of responsibility from which they were otherwise excluded. ${ }^{38}$ This nineteenth-century process of "institution building" was linked to a broader middle-class women's culture characterised by religiosity, moral superiority, and sexual purity. ${ }^{39}$ Whilst predominantly a practical response to their marginalisation from mainstream professional society, women-run medical schools and hospitals also provided alternative sites for socialisation to forge collective identities. ${ }^{40}$ Delivering the annual address to the next generation of women doctors at her alma mater, the London School of Medicine for Women (LSMW), in 1904, Hullbased physician Dr Mary Murdoch advised the students "not to adopt any uncommon style of dress" and to "keep to the fashion of the day without devoting too much care and thought to it". ${ }^{41}$ According to her biographer, Murdoch heeded her own advice and was usually seen wearing "a severe style of dress and the plainest of hats". ${ }^{42}$ This was, in part, a cultivated strategy to minimise further attention: already transgressing gendered norms in through their occupational role, to also do so in their personal appearance risked attracting further commentary from the press and contemporary critics. At the same time, her recommendation accorded with gendered notion of

\footnotetext{
${ }_{37}$ University of Manchester Library [UML]: GB 133 TFT/1/1267/1, Letters from Sophia Weitzman, Personal: Job Prospects, 21 May 1925. I was initially made aware of this source through Cath Feely, 'Securing an Academic Career: Past and Present', 15 May 2017, https://universityhistories.com/2017/05/15/securing-an-academic-career-past-andpresent/.

38 Mary Ann Elston, “'Run by Women, (mainly) for Women”: Medical Women's Hospitals in Britain, 1866-1948', in L. Conrad \& A. Hardy (eds), Women and Modern Medicine (Amsterdam, 2001), p.77.

${ }^{39}$ Martha Vicinus, Independent Women: Work and Community for Single Women, 1850-1920 (London, 1985), p.9.

${ }^{40}$ Elston, “Run by Women, (mainly) for Women", p.74.

${ }^{41}$ Mary Murdoch, 'Practical Hints to Students. An Address to Medical Students, London School of Medicine for Women, October, 1904' in Hope Malleson, A Woman Doctor. Mary Murdoch of Hull (London, 1919), p.170.

${ }^{42}$ Malleson, $A$ Woman Doctor, p.25.
} 
service which characterised nineteenth-century ideas of women's medical work. Murdoch continued that "it is one's duty to the world by which and in which one lives to dress as well as possible without wasting one's substance". ${ }^{43}$ Such advice was situated within a wider framework of self-sacrifice, respectability, philanthropy, and mission: by not expending too much time and energy on their appearance, women were signalling their professional commitment. ${ }^{44}$

Whilst careful to adhere to contemporary styles for fear of compromising their fragile occupational status, practicality was an issue for those whose work entailed long days in the hospital ward or visiting patients across towns and cities. The Edwardian fashion of severely tailored long skirts, bulky layers, stiff collars, bloomers, boned stays, belts, buckles, and laced boots could be physically restrictive as well as time consuming. Isabel Hutton recalled the impracticality of quickly donning these items when called to a medical emergency in Glasgow's slums, referring to them as "great time-wasters". Although women expressed frustration at restrictive clothing, they were often careful not to diverge significantly from contemporary styles, opting instead to make minor adjustments and modifications to their attire. Based on her own professional experience, Murdoch advised female medical students to adopt practical "warm but light, clothing" and minimise the number of layers, including the dress, to three. ${ }^{46}$ She also warned against "tightlacing, or lacing at all", outlining the "evil effects" of the corset she had witnessed in the dissectingroom. ${ }^{47}$ By the late nineteenth century, doctors, health reformers, women's rights campaigners and educationists began to point to the potentially damaging effects of long, full skirts, heavy petticoats, and corsets on women's health. But, while the rational dress movement encouraged practical clothing for women, it failed to have any widespread impact before the First World War. ${ }^{48}$ Women in the pre-war years, still lacking basic political rights, had to navigate a precarious line: predominantly focusing on political reform as a means to challenge their subordinate place in wider society, any visible or physical transgression of gender norms could compromise their fragile professional positions and often constituted a greater symbolic challenge than many were able to make.

Self-fashioning could also be a key site of generational conflict. Scrutinised in a way that their male counterparts were not, the precarity of women's occupational status made them acutely

\footnotetext{
${ }^{43}$ Murdoch, 'Practical Hints to Students', p.170.

${ }^{44}$ Alison Bashford, Purity and Pollution: Gender, Embodiment and Victorian Medicine (Basingstoke, 1998).

${ }^{45}$ Hutton, Memories of a Doctor, p.64.

${ }^{46}$ Murdoch, 'Practical Hints to Students', p.170.

${ }^{47}$ Murdoch, 'Practical Hints to Students', p.170.

${ }^{48}$ Diana Crane, Fashion and its Social Agendas: Class, Gender, and Identity in Clotbing (Chicago, 2000), p.101.
} 
aware of the reputational effects their conduct and self-presentation could have on their successors and on the women's movement more broadly. Dr Elizabeth Garrett Anderson expressed dismay at the way one of her medical students dressed, suggesting that it was "most damaging to the cause". ${ }^{49}$ She lamented how one of her students looked "awfully strong-minded in walking dress $[\ldots]$ she has short petticoats and a close round hat and several dreadfully ugly arrangements". ${ }^{50}$ As the first woman to qualify as a physician in Britain and a figurehead of the medical women's movement, Garrett Anderson had experienced first-hand the dissection of her appearance, manner and work by the press, and was highly conscious of the instability of the public acceptance of women doctors. Respectability was a major consideration for these early pioneers whose ability to found women's medical institutions was precariously dependent on the goodwill and financial patronage of their middle-class networks. A former student of Garrett Anderson recalled how she understood "the art of dressing well" and reportedly said to one of her junior doctors "now put on your smartest evening gown, my dear, I want you to come with me to a reception, and show them that a woman house surgeon can look pretty and be charming". ${ }^{51}$

Women's medical schools sought to instil in their students the collective responsibility they had in upholding the reputation of all women doctors. Murdoch, who had also undertaken her medical training under the deanship of Garret Anderson, echoed her predecessor's sentiments in her address to students at the LSMW in 1904:

Many a badly dressed woman has passed through this School and Hospital in pure loftiness of mind thinking that it did not matter. But it does matter; the great unthinking world judges by external appearances, and the whole body of medical women has been condemned as frumps because a few are careless of their personal attire. ${ }^{52}$

Both Garrett Anderson and Murdoch encouraged medical women to abide by dominant norms of respectable femininity to counter the negative depictions in circulation. They were sensitive to the fact that women were still treated as a homogenised group, and that their physical appearance could compromise their professional reputation and any hard-won gains. But their concerns also hint at tensions between the first generations of pioneers who founded networks and institutions,

\footnotetext{
${ }^{49}$ Ray Strachey, The Cause. A Short History of the Women's Movement in Great Britain (1928; repr., London, 1978), p.173.

${ }^{50}$ Strachey, The Cause, p.173.

${ }^{51}$ Louisa Martindale, The Woman Doctor and her Future (London, 1922), p.61.

52 Murdoch, 'Practical Hints to Students', p.170.
} 
and their successors who - though their entry into medicine was still not without difficulties - had benefited from the paths forged by those before them.

The outbreak of the war in 1914 posed new opportunities for women's self-fashioning in a professional context. At the beginning of the conflict, when they comprised around 1,000 on the Medical Register, women formed voluntary medical units and offered their expertise to the British War Office and Allied nations. Whilst the British authorities initially rejected their offer, in 1915 they invited one of the organisations, the Women's Hospital Corps (WHC), to run a military hospital in London. ${ }^{53} \mathrm{~A}$ visible expression of women's collective professional identity can be seen in the uniform design for these all-women medical units. Writing a history of the WHC in the immediate aftermath of the conflict, founder Dr Flora Murray recalled how they had carefully considered the design to reflect the character of the Corps as "feminine, graceful, [and] businesslike". ${ }^{54}$ The uniform comprised a slightly shorter skirt than pre-war fashions, with a loose, buttoned-up tunic made of a durable and light covert coating. Military overtones were reflected in the buttons, the greenish-grey colour, and the shoulder straps: medical officers had red straps with the Corps initials "W.H.C." sewn in white, while the orderlies had white collars and shoulder straps with red letters. Small cloth hats with veils and overcoats completed what Murray described as "a comfortable and useful outfit". ${ }^{55}$ Fashion historians have argued that women's donning of uniforms was often problematic because they were emblems of authority, status and masculinity. ${ }^{56}$ The self-consciously feminine and practical design of the WHC uniform is therefore symbolic of their growing sartorial assertiveness in a professional context. Several of the senior doctors further adorned their jackets with the purple, white and green badge of the suffrage Women's Social and Political Union. ${ }^{57}$ As J. F. Geddes has argued, the war provided women doctors with an opportunity to contribute to the suffrage campaign and a highly visible platform to demonstrate their professional competency through the all-women medical teams in ways that they had not been able to do before. ${ }^{58}$

\footnotetext{
${ }^{53}$ J. F. Geddes, 'The Women's Hospital Corps: forgotten surgeons of the First World War', Journal of Medical Biography (2006).

${ }^{54}$ Flora Murray, Women as Army Surgeons; being the bistory of the women's hospital corps in Paris, Wimereux and Endell Street (London, 1920), pp.10-11.

55 Murray, Women as Army Surgeons, p.10.

${ }^{56}$ Jennifer Craik, Uniforms Exposed: from conformity to transgression (Oxford, 2005).

${ }^{57}$ Murray, Women as Army Surgeons, p.56.

${ }^{58}$ J. F. Geddes, 'Deeds and words in the suffrage military hospital in Endell Street', Medical History, 51, 1 (2007), 79_ 98
} 
Whilst those qualifying during or immediately after the First World War had more opportunities to gain clinical experience compared to their predecessors, their increased entry into mixed-sex medical schools and training hospitals posed new cultural and social territory for them to navigate. ${ }^{59}$ There were also clear continuities in the personnel and ideologies of pioneer medical women who qualified in the late nineteenth century, had served with women's medical units during the war and were still active in feminist circles in the immediate aftermath. Louisa Martindale attended LSMW during the final decade of the nineteenth century entered into a medical partnership with Mary Murdoch in Hull, before serving with the Scottish Women's Hospitals during the war. In her review of the position of women in medicine in 1922, Martindale outlined that "good manners, suitable and pretty clothes" were "all-important items in the summing up of ultimate success and useful service" ${ }^{60}$ Martindale's advice to prospective medical students was still framed through the notion of service: she argued that it was their professional duty to dress well, "for it is unnecessarily annoying to be a patient to have to put up with slovenly and ugly things". ${ }^{61}$ Indeed, for many women, their sartorial choices continued to be constrained by a framework of service and duty to their patients, rather than for their own pleasure or self-expression.

\section{Fashion, Feminism and the Professional Self}

The influence earlier generations of women had on their professional successors extended beyond the practical advice analysed in the previous section, to their physical embodiment of alternative models of behaviour, attire and deportment. A common feature in the autobiographies of early women doctors and academics is the importance of visible representation of women in similar roles. As a retrospective source, memoirs are both informed by the time in which they were composed and the period in the past they recall. ${ }^{62}$ These testimonies, written many years later in post-war Britain, hint at the tension the authors faced both remembering and reconciling their own experience with contemporary representations. In the composition of their life stories, authors often drew upon two extreme cultural frameworks available to them: either of the dowdy "intellectual frump", or their admiration for a glamorous and fashionable peer. Analysing the narratives in the life-histories of early women doctors, Carol Dyhouse suggests that they had to "invent new plots and new narratives in which the quest for learning and meaningful work would

\footnotetext{
${ }^{59}$ Elston, “'Run by Women, (mainly) for Women”", p.95.

${ }^{60}$ Martindale, The Woman Doctor and her Future, p.114.

${ }^{61}$ Martindale, The Woman Doctor and her Future, p.114.

62 Summerfield, Histories of the Self, p.84.
} 
assume a central role". ${ }^{63}$ In a similar way, unable to identify with cultural representations of professional women, the following reminiscences highlight how previous generations could provide their successors with an alternative professional model from the default prescriptions built around a male body.

On entering medical school in Edinburgh in the first decade of the twentieth century, Isabel Hutton recalled how the women students "employed no aids to beauty" and their "well-washed faces were innocent of even a vestige of powder". ${ }^{4}$ Hutton's recollections also encapsulate the hostility they encountered from their male peers, noting that "it was clear that mannish suits and hob-nailed boots were less frowned upon than lace on the petticoat." ${ }^{65}$ Whilst the reactions they received from contemporaries were an important element in how they conceptualised their professional self in a predominantly masculine occupational culture, interactions with other women in similar occupational roles increasingly provided them with alternative cultural scripts to frame their identities in new ways. Vividly remembering Alice Hutchinson, the senior physician in charge of St John Dispensary in Edinburgh where she subsequently undertook her training, Hutton mused: "I saw in this charming woman a model for all I wished to be myself" ${ }^{66}$ Admiring the respect Hutchinson earned from her patients and students, Hutton continued: "She was a wise and observant physician [...] Tiny and pretty, she dared to be feminine, and her red-gold hair and gay attire brightened the wynds of the Canongate." ${ }^{67}$ As one of the first senior women Hutton encountered, Hutchinson provided her with a new professional template through her embodiment of both feminine traits and professional authority. Similarly, one of the first women professors in Britain, Edith Morley also recalled the admiration she felt for her academic peer and fellow early female professor, Caroline Spurgeon: "attractive and possessed of great personal charm and a delightful speaking voice, she also excelled in everything she undertook." ${ }^{68}$ These recollections served to counteract negative depictions of early professional women in circulation in popular culture at both the time of writing and in the early twentieth century.

Economic historian Dorothy Marshall also wrote of her indebtedness to Eileen Power, her former tutor and academic mentor at Girton and the London School of Economics, for showing

\footnotetext{
${ }^{63}$ Carol Dyhouse, 'Driving Ambitions: women in pursuit of a medical education, 1890-1930', Women's History Review, 7, 3 (1998), p.325.

${ }^{64}$ Hutton, Memories of a Doctor, p.101.

${ }^{65}$ Hutton, Memories of a Doctor, p.40.

${ }^{66}$ Hutton, Memories of a Doctor, p.75.

${ }^{67}$ Hutton, Memories of a Doctor, p.75.

${ }^{68}$ Edith Morley, Before and After: Reminiscences of a Working Life, edited by Barbara Morris, (Reading, 2016), p.53.
} 
her that "that academic brilliance and feminine charm were not mutually exclusive". ${ }^{69}$ In her autobiography, she recalled the impact that Power had on her own reconciliation of her gender and academic identities:

I thought of academic women as being a superior class apart. Dress, appearance, female charm were all beneath me [...] Eileen Power changed all that. She was a charming, beautiful creature, open and friendly in her manner, well groomed, well dressed and so attractive. ${ }^{70}$

In an oral interview with the historian Maxine Berg, Marshall also recalled how Power's influence had "saved [her] from ever becoming an intellectual frump". ${ }^{71}$ Whilst Marshall drew upon the negative cultural motifs about educated women which were available to her, she simultaneously used Power - a well-known figure for both her academic reputation and sartorial elegance - to challenge these derogative images. Her reminiscences also highlight the formative experience she experienced at Girton and the London School of Economics in the immediate aftermath of the war. At these institutions Eileen Power was at the centre of a network of women economic historians throughout the interwar years which, as Carol Dyhouse has suggested, "owed something to her personal attractiveness; her energy, charisma and the air of glamour that surrounded her". ${ }^{72}$ Whilst perhaps atypical among academic women for her time, the pleasure she took in her clothes and self-presentation played an important role in shaping public perceptions of professional women and clearly had a profound influence on successive generations of women who came under her mentorship.

During the 1920s women's appearance also underwent significant changes: cropped hair, risen hemlines and looser, dropped waists came into fashion, while female athleticism and physical culture were celebrated as emblems of modernity. ${ }^{73}$ Interwar Britain witnessed the rise of a massmarket beauty culture where cosmetics and fashionable clothing were cheaper, more accessible and an external signifier of modern femininity. ${ }^{74}$ At a time when young, single working-class

\footnotetext{
${ }^{69}$ Dorothy Marshall, The Making of a Twentieth Century Woman: A Memoir (London, 2003), p.58.

${ }^{70}$ Marshall, The Making of a Twentieth Century Woman, pp.57-8.

${ }^{71}$ Marshall, The Making of a Twentieth Century Woman, p.394.

${ }^{72}$ Dyhouse, No distinction of sex?, p.146; See also: Maxine Berg, A Woman in History: Eileen Power 1889-1940 (Cambridge, 1996).

${ }^{73}$ Ina Zweiniger-Bargielowska, 'The Making of a Modern Female Body: beauty, health and fitness in interwar Britain', Women's History Review, 20, 2 (2011).

${ }^{74}$ Ina Zweiniger-Bargielowska, 'The Body and Consumer Culture' in Zweiniger-Bargielowska (ed), Women in TwentiethCentury Britain: Social, Cultural and Political Change (2001); Cheryl Buckley and Hilary Fawcett, Fashioning the Feminine: Representation and Women's Fashion from the Fin de Siecle to the Present (London, 2002), p.4.
} 
women had greater purchasing power, women journalists praised the democratisation of dress which made it less easy to "distinguish a factory girl from the unoccupied daughter of an urban landowner". ${ }^{75}$ Ina Zweiniger-Bargielowska argues that this transformation in women's appearance reflected the emergence of "an assertive femininity which arguably was more liberated than its nineteenth-century construction but, more importantly, which emphasised heterosexual physical attractiveness and was democratically available". ${ }^{76}$

In this more fluid cultural and social context, prominent interwar feminists began to publicly address the uneasy alliance between self-fashioning and professional identity in their writing. Outlining this problem which she considered all professional women faced at some point, writer and journalist Winifred Holtby asked in the Manchester Guardian: "ought we to abandon an interest in our clothes?" 77 She continued: "today a large number of the women who undertake public and professional work decide that they have no time to be bothered about clothes. Some definitely disapprove of attempts by women to appear attractive". ${ }^{78}$ For many women, Holtby outlined, an adherence to the latest fashions or investment in one's personal appearance was considered to detract attention away from the performance of "valuable service to the community". ${ }^{79}$ Such sentiments show clear continuities with pre-war gendered notions of service, which, as Eve Colpus has argued, continued to shape constructions of women's identities in the interwar years alongside new ideas of self-fulfilment. ${ }^{80}$ For those whose lives spanned the pre- and post-war generations, professional identities continued to be constructed in relation to notions of duty, vocation and service, and this was visibly expressed through their clothing and personal appearance.

At the same time, some women began to challenge the notion that their professional identity and ability to take pleasure in their personal appearance were mutually exclusive. Holtby neatly conveyed this tension when she wrote:

Under the tyranny of that dilemma women have been told that they cannot both marry and have a career outside the home, that they cannot preserve both domestic and professional efficiency, that they cannot maintain a decorous and exquisite standard

\footnotetext{
${ }^{75}$ Mrs J. L. Stocks, 'The Return of the Long Skirt' (1929). Cited in Mary Stott (ed.), Women Talking: An Anthology from the Guardian Women's Page, 1922-35 · 1957-71 (London, 1987) p.119; Dr Maude Royden, 'The Return of the Long Skirt' (1929). Cited in Stott (ed.), Women Talking, p.118

76 Zweiniger-Bargielowska, 'The Body and Consumer Culture', p.188.

77 Winifred Holtby, 'Fashions and Feminism' (1927). Cited in Stott (ed.), Women Talking, p.112.

${ }^{78}$ Holtby, 'Fashions and Feminism', p.112.

${ }^{79}$ Holtby, 'Fashions and Feminism', p.113.

${ }^{80}$ Eve Colpus, 'Women, Service and Self-actualization in Inter-war Britain', Past \& Present, 238, 1 (2018), p.232.
} 
of taste in their own appearance and in their possessions, and at the same time perform useful service to the public. And only a few of the very brave or very wise have yet replied to the proposers of the alternatives "We will have both". ${ }^{8}$

Holtby challenged the false dichotomies of private and public, personal and professional, service and self-fulfilment. Moreover, she questioned the idea that taking pleasure in one's personal appearance compromised professional seriousness. Writing on the advent of the extension of the franchise to women on the same terms as men in 1928, Holtby's writing suggests that some women were becoming more assertive in their sartorial choices in the workplace. Indeed, subtle shifts in the political, social and cultural climate of the interwar decades allowed some women to selffashion new feminine professional identities, and feminist campaigners increasingly sought to show that professional and personal lives were not incompatible. Though not always clear-cut, subtle generational differences existed in the social and cultural context for women entering the workforce in the Edwardian years and those who reached adolescence during and after the war. While the earlier generation had focused on political reform and breaking down overt barriers to entry in some occupations, subsequent generations began to target the cultural legacies of those exclusions. This, too, was reflected in how women constructed their professional identities and reconciled it with gender norms in relation to their personal appearance.

\section{Conclusion}

By charting the difficulty women faced embodying professional identities from the late nineteenth century to the interwar decades, this article has sought to shed further light on the way cultural practices, as well as the more overt economic and legal barriers, maintained exclusivist claims to expertise. Boundaries of professionalism were also visibly expressed and subverted through the gendered body: a complex mesh of height, physique, clothing and deportment served as tangible signifiers of abstract professional ideals, and markers of gender conformity or transgression. The default embodied professional remained resolutely male, and this contributed to the marginalisation of those historically excluded from specific occupations and roles on account of their gender. Emphasis on physical difference was one way for the professional establishment to maintain hierarchical distinctions between men and women - a distinction which was becoming increasingly difficult to maintain following their admission to examinations and professional bodies.

\footnotetext{
${ }^{81}$ Holtby, 'Fashions and Feminism', p.113.
} 
Derogative caricatures of women who transgressed gendered norms in their work certainly legitimatised gendered notions of power and professional authority in broader society and culture. But women's retention of newspaper clippings which contained descriptions of their physical attributes and dress, often marked with crosses and preserved in scrapbooks in personal archive collections, demonstrates that they were acutely aware of the scrutiny their appearance was subject to on a personal level. ${ }^{82}$ Women's testimonies provide a glimpse into how they remembered and reconciled their gender and professional identities in relation to their physical appearance. For the first generations of women entering medicine, this was a particularly delicate balancing act. Precarious in their occupational positions, they were conscious of the reputational effects their appearance could have on both their women-run medical institutions, and on women doctors more broadly. A rejection of self-adornment signalled a commitment of their time and energy to their work, as well as serving to downplay external markers of femininity.

The development of female professionalisation and women-run institutions provided spaces for women to forge collective identities and offer practical advice to their peers on selffashioning in a professional context. At the same time, visible representation of other women in their field offered new cultural scripts and models of behaviour for their successors to conceptualise their own identities. Against a continuing backdrop of scrutiny, those entering the workforce in the interwar years were operating in a subtly different context to their pre-war counterparts. The more fluid fashions and political landscape of the interwar years gave women greater scope for a more assertive form of femininity. Whilst the ability for individual expression was always more limited for women, a few notable interwar figures provided alternative templates for successive generations under their mentorship, allowing them to reconcile their gender and professional identities through their physical appearance in alternative - albeit, still restricted ways. Yet, as contemporary research into gender and professional culture has shown, the cultural legacy of women's historic marginalisation in professional society still has profound and enduring effects on their embodied experiences in the workplace today. ${ }^{83}$

82 WL: 7HLN/A/04, Helena Normanton, Press Clippings; NLW: 2778, Professor Mary Williams Press Clippings 1923-1936.

${ }^{83}$ Haynes, 'Body Beautiful?', pp.489-507. 